\title{
Comparison of the Radiological Hazard of Thorium and Uranium Spent Fuels from VVER-1000 Reactor
}

\author{
Jan Frybort \\ Department of Nuclear Reactors, V Holesovickach 2, Prague 8, 180 00, Czech Republic
}

\begin{abstract}
Thorium fuel is considered as a viable alternative to the uranium fuel used in the current generation of nuclear power plants. Switch from uranium to thorium means a complete change of composition of the spent nuclear fuel produced as a result of the fuel depletion during operation of a reactor. If the Th-U fuel cycle is implemented, production of minor actinides in the spent fuel is negligible. This is favourable for the spent fuel disposal. On the other hand, thorium fuel utilization is connected with production of ${ }^{232} \mathrm{U}$, which decays via several alpha decays into a strong gamma emitter ${ }^{208} \mathrm{Tl}$. Presence of this nuclide might complicate manipulations with the irradiated thorium fuel.

Monte-Carlo computation code MCNPX can be used to simulate thorium fuel depletion in a VVER-1000 reactor. The calculated actinide composition will be analysed and dose rate from produced gamma radiation will be calculated. The results will be compared to the reference uranium fuel. Dependence of the dose rate on time of decay after the end of irradiation in the reactor will be analysed. This study will compare the radiological hazard of the spent thorium and uranium fuel handling.
\end{abstract}

Keywords: spent thorium fuel, spent uranium fuel, radiological hazard, MCNPX

\section{Alternative Thorium Nuclear Fuel}

Nuclear power plants (NPP) use appropriate fuel materials which can be fissioned by neutrons to maintain a fission chain reaction to generate thermal power. This is later transformed in electricity. Majority of the current NPP utilize uranium as the nuclear fuel. Thorium can be considered as a viable alternative. Natural thorium does not contain any fissile material. It can be added in various forms. This study will focus on thorium fuel supported by ${ }^{233} \mathrm{U}$, which is created by capturing a neutron by ${ }^{232} \mathrm{Th}$ nucleus (pure Th-U fuel cycle, similar to U-Pu fuel cycle). As uranium fuel properties are well known, it is not necessary to calculate absolute values. It is sufficient to focus on stating the spent thorium fuel characteristics relative to the reference uranium fuel.

This study compares radiological hazard connected with handling of spent uranium and thorium fuels and deals with applicability of general fuel depletion codes to calculation of such characteristics. The same tools are applied in both cases and special attention is payed to ${ }^{232} \mathrm{U}$ and products of its decay.

\subsection{Spent Thorium Fuel}

From neutronic point of view, it is possible to replace the enriched uranium fuel with thorium supported by ${ }^{233} \mathrm{U}$. These alternatives do not only have different neutronic properties during fuel depletion in a reactor, but there are also differences when the spent nuclear fuels are compared. As the fuel is irradiated by neutrons in a nuclear reactor, not only fission products, but also new actinides are created as a result of non-fissile neutron capture reactions. This is the source of plutonium and higher transuranium elements. Replacing the uranium with thorium leads to radically different actinide composition in the spent nuclear fuel.

\subsection{Contamination by ${ }^{232} U$}

Spent thorium nuclear fuel can have various compositions depending on the supporting fissile material. In any case, ${ }^{232} \mathrm{U}$ is created mainly by the following reaction on ${ }^{232} \mathrm{Th}$ :

$$
{ }^{232} \mathrm{Th} \underset{2 \mathrm{n}}{\stackrel{\mathrm{n}}{\longrightarrow}}{ }^{231} \mathrm{Th} \underset{25.52 \mathrm{~min}}{\stackrel{\beta^{-}}{\longrightarrow}}{ }^{231} \mathrm{~Pa}+\mathrm{n} \longrightarrow{ }^{232} \mathrm{~Pa} \underset{1.31 \mathrm{~d}}{\stackrel{\beta^{-}}{\longrightarrow}}{ }^{232} \mathrm{U} .
$$

This uranium nuclide contaminates the fuel mixture with concentration depending on the fuel burnup. It is important, because ${ }^{232} \mathrm{U}$ decays with 69 years half-life via ${ }^{228} \mathrm{Th}$ and several other short-lived nuclides into ${ }^{208} \mathrm{Tl}$, which is a source of 2.6 MeV gamma radiation (Kang and von Hippel, 2001). Importance of this strong gamma emitter for properties of the spent thorium fuel in the time frame typical for fuel handling and reprocessing will be analysed in this study.

The kinetics of ${ }^{208} \mathrm{Tl}$ production by decay of the spent thorium fuel with assumption that no ${ }^{208} \mathrm{Tl}$ was present in the spent fuel at the end of irradiation and that ${ }^{208} \mathrm{Tl}$ is produced exclusively by ${ }^{232} \mathrm{U}$ decay is shown in Fig. 1 . The ${ }^{208} \mathrm{Tl}$ concentration relative to ${ }^{232} \mathrm{U}$ reaches maximum at $10-15$ years after the end of irradiation. It is possible to calculate ratio of ${ }^{208} \mathrm{Tl}$ number density to ${ }^{232} \mathrm{U}$ number density to assess the ${ }^{208} \mathrm{Tl}$ effect even though its atom fraction is not available from the fuel depletion calculation (see section 3). 


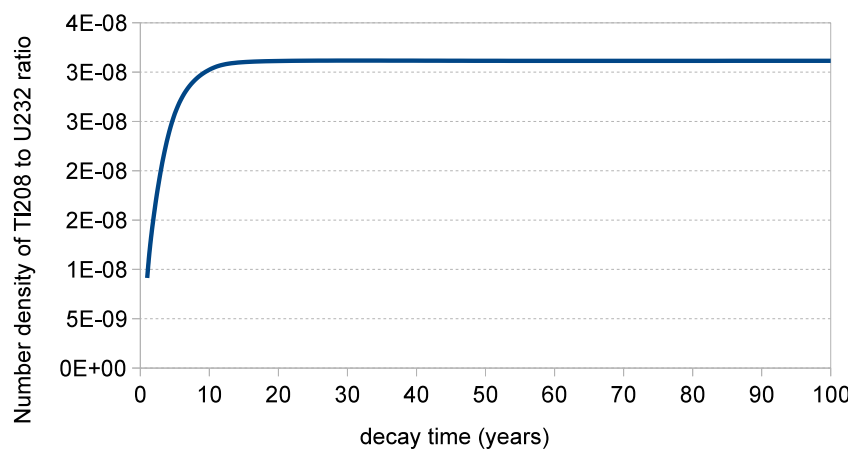

Figure 1: Ratio of ${ }^{208} \mathrm{Tl}$ number density produced by ${ }^{232} \mathrm{U}$ decay to ${ }^{232} \mathrm{U}$ number density

\section{Analysis Fundamentals}

This analysis is aimed at characterisation of the spent nuclear fuel. Handling of the spent uranium fuel is well established Cacuci (2010), therefore it is sufficient to focus only on differences between the spent thorium and uranium fuels. It was first necessary to calculate compositions of the spent fuels for both alternatives. These compositions were later used for relative comparisons of spectra of emitted gamma radiation and basic gamma dose rate characteristics.

All results are relative to the same spent fuel volume and not its mass. When thorium is to replace uranium in the current design of fuel assemblies, it will occupy the same volume despite its lower density, thus results of this study can be used as a comparison of the alternative fuel assemblies.

\subsection{Fuel Depletion}

Monte Carlo code MCNPX in version 2.7 (Pelowitz, 2011) with default settings was utilized to calculate an average composition of the spent thorium and uranium fuels. MCNPX has the capability to couple neutron transport calculation with fuel depletion to provide time evolution of irradiated materials. The input model geometry and composition of the fresh fuel for equilibrium cycles was determined as a result of a separate study (Frybort and Vocka , 2010) and it is specific to VVER1000 reactor operated in $4 \times 12$ months cycle. Initial enrichment (weight fraction of ${ }^{233} \mathrm{U}$ ) of the thorium fuel was $4.15 \%$. Uranium enrichment $\left({ }^{235} \mathrm{U}\right.$ weight fraction) was $4.70 \%$. Both fuels were depleted to reach final burnup $44.5 \mathrm{MWd} / \mathrm{kg}_{\mathrm{HM}}$. Afterwards it was left to decay for 50 years and the change of the spent fuel composition was recorded. ENDF/B-VII.0 nuclear data library Chadwick (2006) was utilized.

Both fuel types have similar final multiplication factor. The fuel depletion calculation was conducted essentially in 2D environment in an infinite geometry realized by a reflective boundary condition applied on all outer boundaries, thus it is necessary to talk about infinite multiplication factor. Height of the model is $1 \mathrm{~cm}$. It is important for later data regarding the mass of fuel. Horizontal cross-section through the calculational model is in Fig. 2. Plot of development of the infinite multiplication factor during fuel depletion is in Fig. 3. Standard

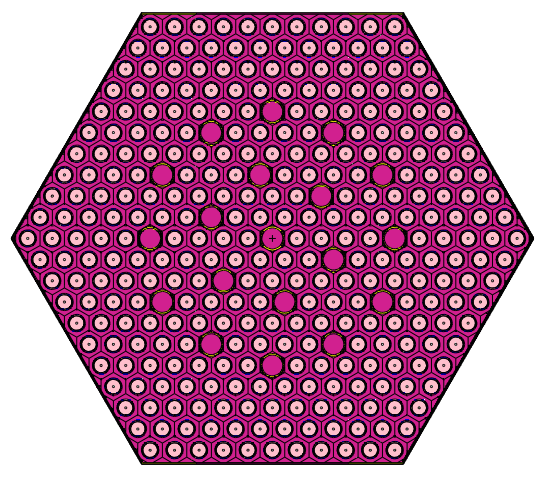

Figure 2: Horizontal cross-section through the depletion calculation model

deviation of the multiplication factor determination was in the range from 0.0035 to 0.0040 during the depletion.

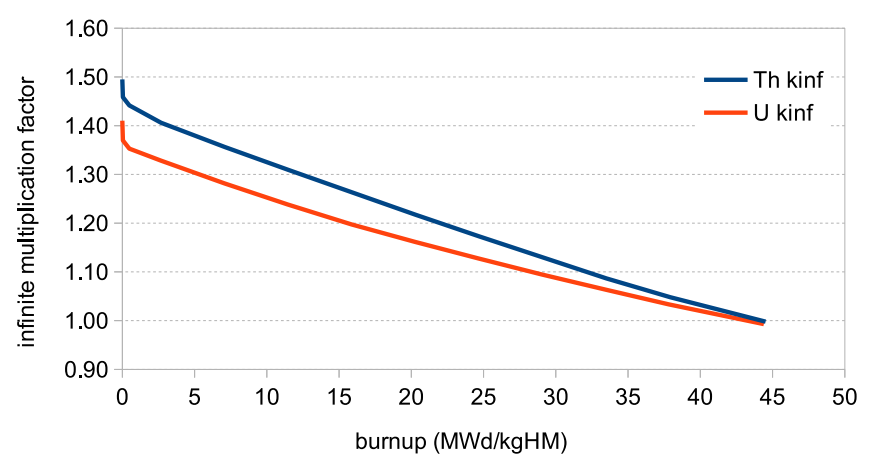

Figure 3: Infinite multiplication factor during fuel depletion

This study is not focused on calculation of balance of materials in uranium and thorium fuel cycles. Evaluation of various thorium fuel designs in VVER-440 reactor can be found in Breza (2010).

\subsection{Composition of Spent Fuel}

The MCNPX code divides nuclides into two basic groups: actinides and fission products (FPs). The group of fission products contains also oxygen, which is presented at high quantity due to oxide form of the fuels. Fuel depletion changes the fuel composition. Initially, the fuel was composed only from ${ }^{235} \mathrm{U}$, ${ }^{238} \mathrm{U}$, and ${ }^{16} \mathrm{O}$ in the enriched uranium case; and from ${ }^{233} \mathrm{U}$, ${ }^{232} \mathrm{Th}$, and ${ }^{16} \mathrm{O}$ in case of thorium fuel. Tab. 1 gives an overview of mass of actinides and FPs at the beginning (BOL) and end of fuel depletion (EOL) in the calculational model. The group of fission products excludes oxygen (forms about $76 \%$ of mass of all FPs).

More details are provided in Tab. 2 giving mass of the dominant fission products at the end of fuel depletion. This selection contains nuclides with share on the mass of FPs without oxygen greater than $0.5 \%$ in either of the fuels. Total, these nuclides makes more than $93 \%$ of fission products in the uranium fuel and almost $94 \%$ in the thorium fuel.

Similar data to fission products are also prepared for actinides at EOC in Tab. 3. There are shares of individual nuclides 
Table 1: Mass of actinides and fission products (except oxygen) at BOL and EOL

\begin{tabular}{lcc|cc}
\hline & \multicolumn{2}{c|}{ uranium fuel } & \multicolumn{2}{c}{ thorium fuel } \\
time & actinides & FPs & actinides & FPs \\
\hline BOL & $1266 \mathrm{~g}$ & - & $1157 \mathrm{~g}$ & - \\
EOL & $1207 \mathrm{~g}$ & $54.8 \mathrm{~g}$ & $1103 \mathrm{~g}$ & $51.8 \mathrm{~g}$ \\
\hline
\end{tabular}

Table 2: Share of selected nuclides on mass of fission products at EOL

\begin{tabular}{ccc|ccc}
\hline FP & uranium & thorium & FP & uranium & thorium \\
\hline $\mathrm{Kr} 84$ & $0.34 \%$ & $0.74 \%$ & $\mathrm{Te} 130$ & $1.14 \%$ & $1.18 \%$ \\
$\mathrm{Kr} 86$ & $0.61 \%$ & $1.07 \%$ & $\mathrm{I} 129$ & $0.43 \%$ & $0.80 \%$ \\
$\mathrm{Rb} 85$ & $0.28 \%$ & $0.63 \%$ & $\mathrm{Xe} 131$ & $1.24 \%$ & $1.36 \%$ \\
$\mathrm{Rb} 87$ & $0.77 \%$ & $1.53 \%$ & $\mathrm{Xe} 132$ & $3.30 \%$ & $3.52 \%$ \\
$\mathrm{Sr} 88$ & $1.07 \%$ & $2.11 \%$ & $\mathrm{Xe} 134$ & $4.65 \%$ & $3.74 \%$ \\
$\mathrm{Sr} 90$ & $1.69 \%$ & $2.56 \%$ & $\mathrm{Xe} 136$ & $6.92 \%$ & $6.85 \%$ \\
$\mathrm{Y} 89$ & $1.36 \%$ & $2.31 \%$ & $\mathrm{Cs} 133$ & $3.27 \%$ & $2.79 \%$ \\
$\mathrm{Zr} 91$ & $1.73 \%$ & $2.33 \%$ & $\mathrm{Cs} 135$ & $1.12 \%$ & $0.89 \%$ \\
$\mathrm{Zr} 92$ & $1.98 \%$ & $2.62 \%$ & $\mathrm{Cs} 137$ & $3.65 \%$ & $3.92 \%$ \\
$\mathrm{Zr} 93$ & $2.15 \%$ & $2.76 \%$ & $\mathrm{~B} 138$ & $3.97 \%$ & $3.60 \%$ \\
$\mathrm{Zr} 94$ & $2.37 \%$ & $2.79 \%$ & $\mathrm{~L} 139$ & $3.72 \%$ & $3.77 \%$ \\
$\mathrm{Zr} 96$ & $2.38 \%$ & $2.34 \%$ & $\mathrm{Ce} 140$ & $3.53 \%$ & $3.81 \%$ \\
$\mathrm{M} 95$ & $1.98 \%$ & $2.14 \%$ & $\mathrm{Ce} 142$ & $3.42 \%$ & $4.18 \%$ \\
$\mathrm{M} 997$ & $2.30 \%$ & $2.26 \%$ & $\mathrm{Ce} 144$ & $1.05 \%$ & $1.08 \%$ \\
$\mathrm{M} 99$ & $2.36 \%$ & $2.18 \%$ & $\mathrm{Pr} 141$ & $3.15 \%$ & $3.67 \%$ \\
$\mathrm{M} 100$ & $2.67 \%$ & $1.90 \%$ & $\mathrm{Nd} 143$ & $2.27 \%$ & $2.36 \%$ \\
$\mathrm{~T} 99$ & $2.22 \%$ & $1.77 \%$ & $\mathrm{Nd} 144$ & $2.85 \%$ & $3.05 \%$ \\
$\mathrm{Ru} 101$ & $2.19 \%$ & $1.30 \%$ & $\mathrm{Nd} 145$ & $1.95 \%$ & $1.87 \%$ \\
$\mathrm{Ru} 102$ & $2.20 \%$ & $1.12 \%$ & $\mathrm{Nd} 146$ & $2.12 \%$ & $1.97 \%$ \\
$\mathrm{Ru} 104$ & $1.49 \%$ & $0.44 \%$ & $\mathrm{Nd} 148$ & $1.13 \%$ & $0.85 \%$ \\
$\mathrm{Rh} 103$ & $1.08 \%$ & $0.39 \%$ & $\mathrm{Nd} 150$ & $0.50 \%$ & $0.33 \%$ \\
$\mathrm{Pd} 105$ & $0.95 \%$ & $0.19 \%$ & $\mathrm{~S} 150$ & $0.75 \%$ & $0.49 \%$ \\
\hline
\end{tabular}

on the total mass of actinides in the spent fuel as it is provided by the MCNPX code.

The differences between uranium and thorium fuels from the above tables are plotted in Fig. 4 and Fig. 5. The first Fig. 4 shows how different yields of fission products of the fissile nuclides affect the final composition of fission products. It can be also seen that yield of fission products in the thorium fuel compared to the uranium fuel is shifted to lighter nuclides. The other Fig. 5 shows how utilization of thorium with ${ }^{233} \mathrm{U}$ fissile material makes production of transuranium elements negligible.

\subsection{Calculational Model and Dose Rate Calculation}

The employed MCNPX code has several calculational modes. One of the options is the possibility to simulate a user defined source of gamma radiation. As the determined spent fuel composition contains almost 200 nuclides, an individual analysis of emission spectra of all these nuclides is highly difficult. For such a purpose, new capability was added in the
Table 3: Share of selected nuclides on mass of actinides at EOL

\begin{tabular}{ccc}
\hline actinide & uranium & thorium \\
\hline Th232 & $0.00 \%$ & $97.29 \%$ \\
Pa231 & $0.00 \%$ & $<0.01 \%$ \\
$\mathrm{U} 232$ & $0.00 \%$ & $<0.01 \%$ \\
$\mathrm{U} 233$ & $0.00 \%$ & $2.14 \%$ \\
$\mathrm{U} 234$ & $0.02 \%$ & $0.46 \%$ \\
$\mathrm{U} 235$ & $1.24 \%$ & $0.09 \%$ \\
$\mathrm{U} 236$ & $0.65 \%$ & $0.01 \%$ \\
$\mathrm{U} 237$ & $<0.01 \%$ & $0.00 \%$ \\
$\mathrm{U} 238$ & $96.91 \%$ & $0.00 \%$ \\
$\mathrm{~Np} 237$ & $0.07 \%$ & $0.00 \%$ \\
$\mathrm{~Np} 239$ & $<0.01 \%$ & $0.00 \%$ \\
$\mathrm{Pu} 238$ & $0.02 \%$ & $0.00 \%$ \\
$\mathrm{Pu} 239$ & $0.61 \%$ & $0.00 \%$ \\
$\mathrm{Pu} 240$ & $0.25 \%$ & $0.00 \%$ \\
$\mathrm{Pu} 241$ & $0.16 \%$ & $0.00 \%$ \\
$\mathrm{Pu} 242$ & $0.06 \%$ & $0.00 \%$ \\
\hline
\end{tabular}

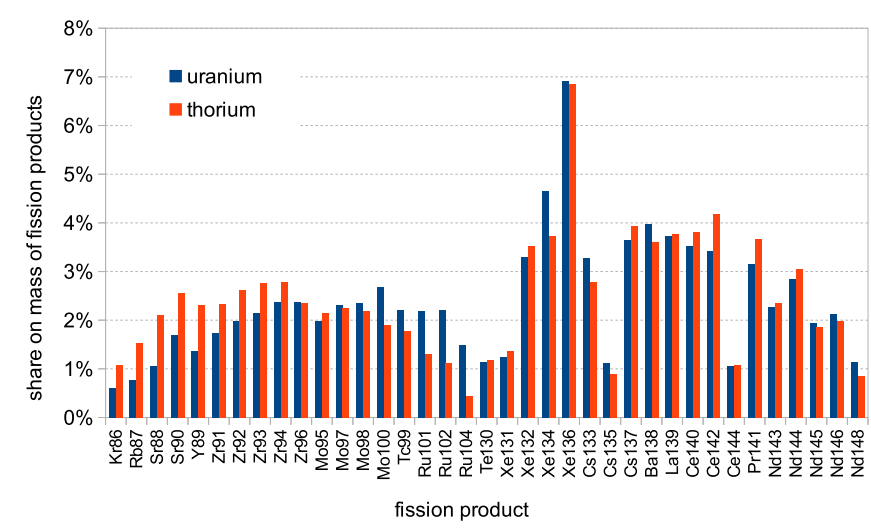

Figure 4: Share of selected nuclides on mass of fission products

MCNPX code. Source of radiation can be defined by its isotopic composition and MCNPX is capable to calculate automatically to corresponding gamma spectrum.

Comparison of dose rate characteristics of the spent thorium and uranium fuels was conducted in two positions in a simple model. In the centre of the geometry, there is a sphere $1 \mathrm{~cm}$ in radius filled with samples of the spent nuclear fuel. This sphere forms a volumetric radiation source for the dose-rate calculations. Given the different densities of the compared fuels, mass of these samples is approx. $40 \mathrm{~g}$ and $44 \mathrm{~g}$ for thorium and for uranium case, respectively. This inner sphere is confined in a set of three concentric spheres. The first one has radius $10 \mathrm{~cm}$ and its inner void volume (outside of the volume of the source) defines the position $\mathrm{A}$ in the following results. Space between this sphere and the second sphere with radius $11 \mathrm{~cm}$ is filled with lead to allow a simple assessment of the gamma radiation attenuation. The final third sphere has radius $20 \mathrm{~cm}$ and void volume between the second and third sphere is designated as 


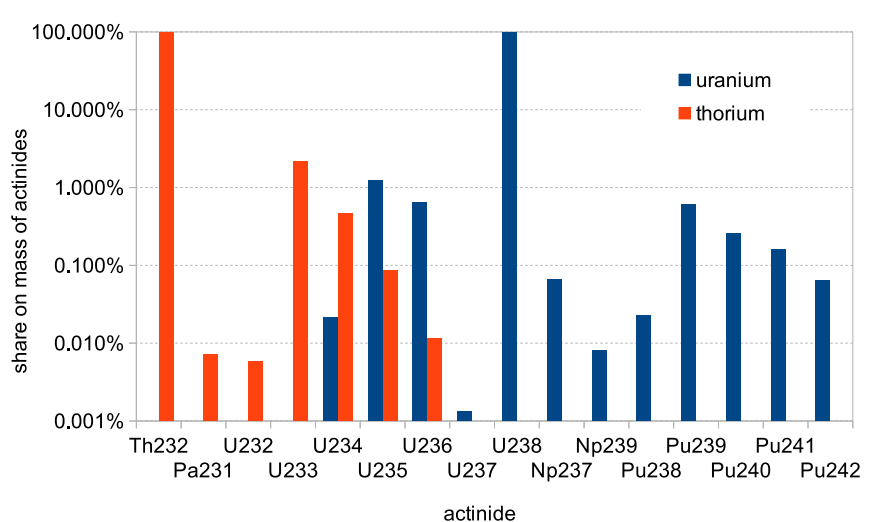

Figure 5: Share of selected nuclides on mass of actinides

position B. Volumes of the respective spheres are arbitrary and serve for recording results of the Monte-Carlo simulation. The only source for the dose-rate attenuation is the lead layer with $1 \mathrm{~cm}$ thickness.

Calculations for both positions were conducted simultaneously, as a result also the gamma spectrum in position $\mathrm{A}$ is affected by the lead layer. The dose rate calculations in both positions were set in the MCNPX input deck by applying the integrated dose function based on ICRP-21 1971, e.g. the corresponding photon flux dose modifier for tally number 24 is following: df 24 IU=2 FAC=1.0 IC=10.

It was desired to keep the statistical error in all energy bins below $1 \%$, therefore the running times were long (10 or more days on 12 core Xeon CPU $2.5 \mathrm{GHz}$ ).

\section{Analysis Results}

First, the results of the fuel depletion calculations were processed. MCNPX has an internal threshold that helps to identify important nuclides for the transport calculation. Nuclides with atomic fraction below $1 \times 10^{-10}$ are regarded as insignificant and they are discarded. It was discovered that actinides in the spent thorium fuel consist only from thorium, protactinium and uranium isotopes. The group of actinides in the spent uranium fuel contained further isotopes of neptunium and plutonium. It was also found that the spent fuel composition did not contain ${ }^{208} \mathrm{Tl}$. It is especially important that no new nuclides appeared in the output during the following decay period. This can lead to omission of important contributors to the overall spent fuel activity during long-term decay period. This can be a problem for isotopes of radium and polonium. It was thus decided to analyse properties of the obtained spent fuel composition and afterwards analyse separately the ${ }^{208} \mathrm{Tl}$ importance.

\subsection{Activity of Actinides}

The spent fuel composition can be logically split into two groups: actinides and fission products. Summary of results for both groups is given in Tab. 4. It can be seen that, except for the beginning, there is a substantially lower actinide activity in the spent thorium fuel. On the other hand, there is higher activity of fission products in the later years and thus, the overall activity of the spent fuel in the possible alternative thorium fuel assembly is getting higher compared to the uranium fuel.

Table 4: Thorium to uranium ratio of activity of the compared samples

\begin{tabular}{cccc}
\hline time & actinides & fission products & total \\
\hline $0 \mathrm{y}$ & 1.361 & 0.986 & 1.143 \\
$1 \mathrm{y}$ & 0.023 & 0.882 & 0.809 \\
$20 \mathrm{y}$ & 0.017 & 1.271 & 0.985 \\
$50 \mathrm{y}$ & 0.050 & 1.262 & 1.085 \\
\hline
\end{tabular}

The observed actinide activity difference is caused by radically different actinide compositions in the compared spent fuels. Actinides contributing to the overall spent fuel activity are shown in Fig. 6. The plot in the figure shows that important actinides in the spent thorium and uranium fuels are almost completely disjoint sets. It is further interesting that despite high mass, ${ }^{235} \mathrm{U}$ and ${ }^{238} \mathrm{U}$ are not important in this regard.

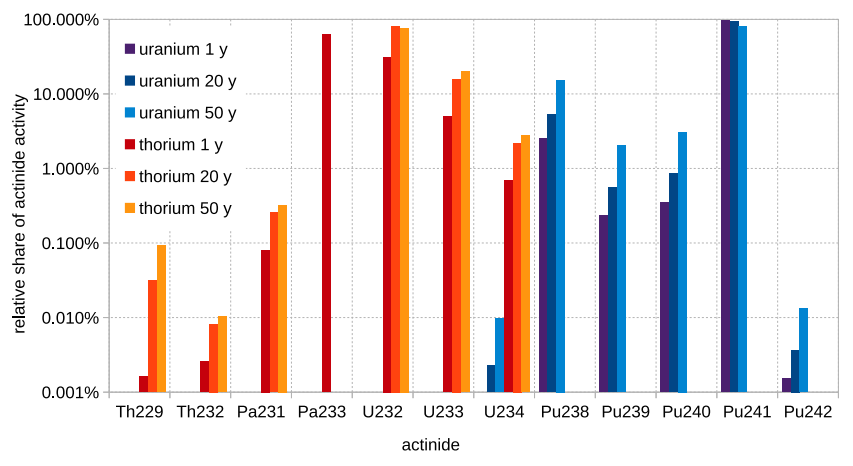

Figure 6: Actinides contributing to the spent fuel activity

\subsection{Activity of Fission Products}

Structure of activity of fission products is similar in both analysed fuel types. The same nuclides are dominant for the spent fuel activity in the analysed period (up to 50 years after the end of fuel depletion). Different are shares of the individual nuclides. The first plot of activity of fission products in Fig. 7 shows share of individual important nuclides on the total activity of fission products in the spent fuel after 1 year of decay. It is compared in Fig. 8 showing the ratio of share of individual nuclides in the thorium and uranium spent fuels after 1 year of decay.

The same nuclides as plotted in Fig. 7 and Fig. 8 are important during the whole analysed decay period, therefore it can be concluded that the further observed spectrum and dose rate differences are a result of different composition of actinides.

\subsection{Gamma Spectrum}

This section deals with the spectrum of gamma radiation produced by the spent nuclear fuel. The calculational procedure 


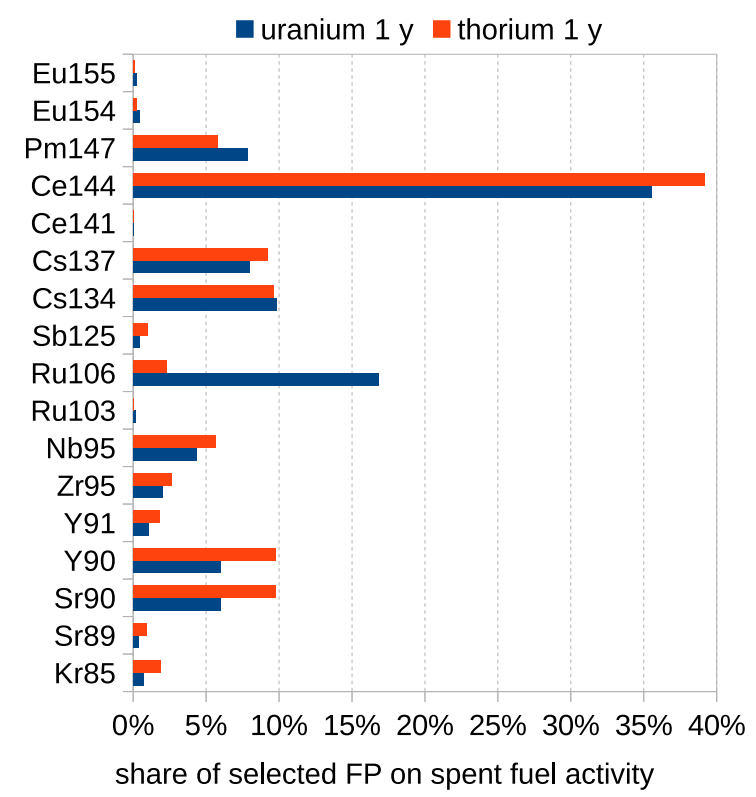

Figure 7: Comparison of activity of dominant fission products in the spent fuel after 1 year of decay

was introduced in section 2. The results were recorded in two positions $\mathrm{A}$ and $\mathrm{B}$ (behind the $1 \mathrm{~cm}$ lead shielding) during the decay time. The plots of gamma spectra are plotted with both axes in logarithmic scale. Ordinates in all plots showing the spectrums for each time step have the same ranges to visualise the decrease of the photon flux caused by the lead layer and time of decay. There are plots showing the results immediately after the end of fuel depletion in the reactor (Fig. 9) and three sets of plots showing the results after 1, 20, and 50 years of decay (Fig. 10, Fig. 11, and Fig. 12).

It can be concluded by comparing the plots that the spectra for the thorium and uranium cases are similar for all time steps, especially for position B. Just after 1 year of decay, the originally observed high peak at about $1.6 \mathrm{MeV}$ is missing. This is caused by decay of ${ }^{124} \mathrm{Sb}$ (half-life 60.2 days), which emits $1.69 \mathrm{MeV}$ gamma radiation with yield $47.6 \%$. Other important persistent contributors to the gamma spectrum are ${ }^{144} \mathrm{Ce}(133 \mathrm{keV})$ and ${ }^{154} \mathrm{Eu}$ (multiple intensive gamma lines at $123 \mathrm{keV}$ and between 0.6 and $1.3 \mathrm{MeV}$ ). No $2.6 \mathrm{MeV}$ gamma radiation cannot be observed due to missing ${ }^{208} \mathrm{Tl}$ in the $\mathrm{MC}$ NPX code output.

\subsection{Dose rate}

In this chapter, the dose rates calculated by MCNPX are compared. It is the most important characteristic of the analysed spent fuels. There are results for both positions A and B in the analysed geometry during the decay time (up to 50 years of decay). The results are present in Tab. 5. The first two columns show ratios of the dose rate for the spent thorium fuel to the spent uranium fuel in the respective positions and decay times. The other two columns show the effect of ${ }^{208} \mathrm{Tl}$ as a ratio of the calculated dose rate for the spent thorium fuel with added ${ }^{208} \mathrm{Tl}$

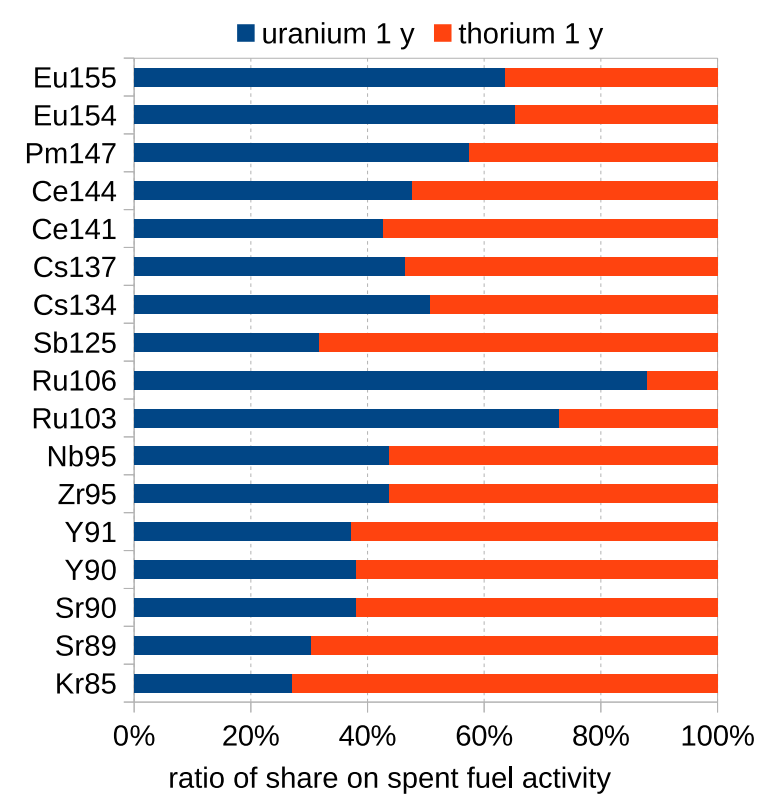

Figure 8: Ratio of share of dominant fission products on the spent fuel activity after 1 year of decay
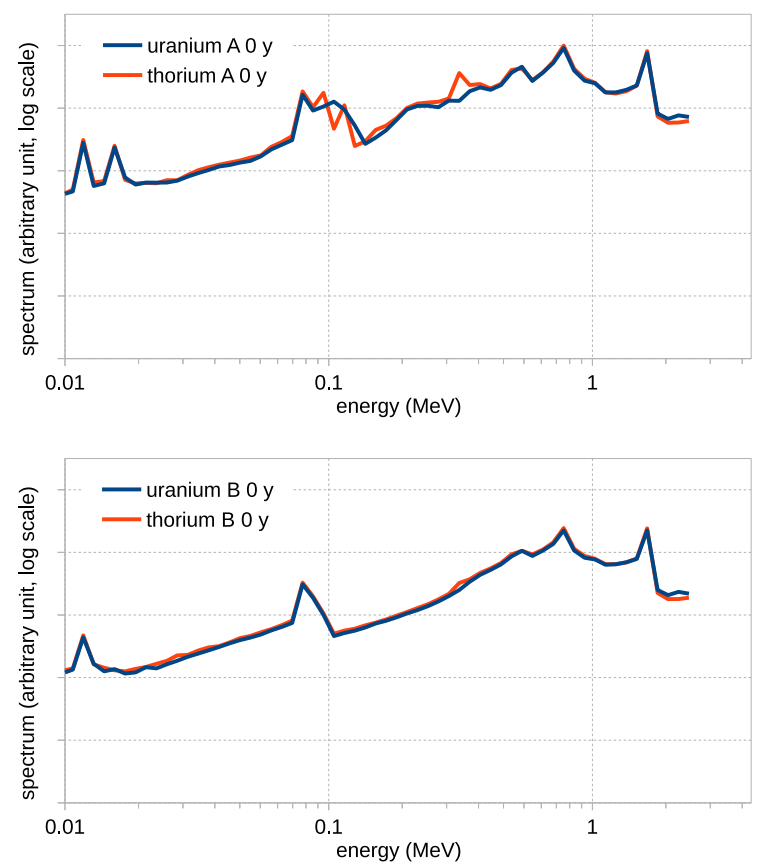

Figure 9: Gamma spectrum in positions A and B immediately after the end of fuel depletion

to the dose rate for the spent thorium fuel with composition determined by the default MCNPX calculation.

The results in Tab. 5 show that despite limited difference of the spent thorium fuel activity compared to spent uranium fuel (less than $10 \%$ for 20 and 50 years of decay), the differences in the gamma spectrum leads to higher dose rates from the spent thorium fuel.

Initially the high dose rate immediately after the end of fuel 

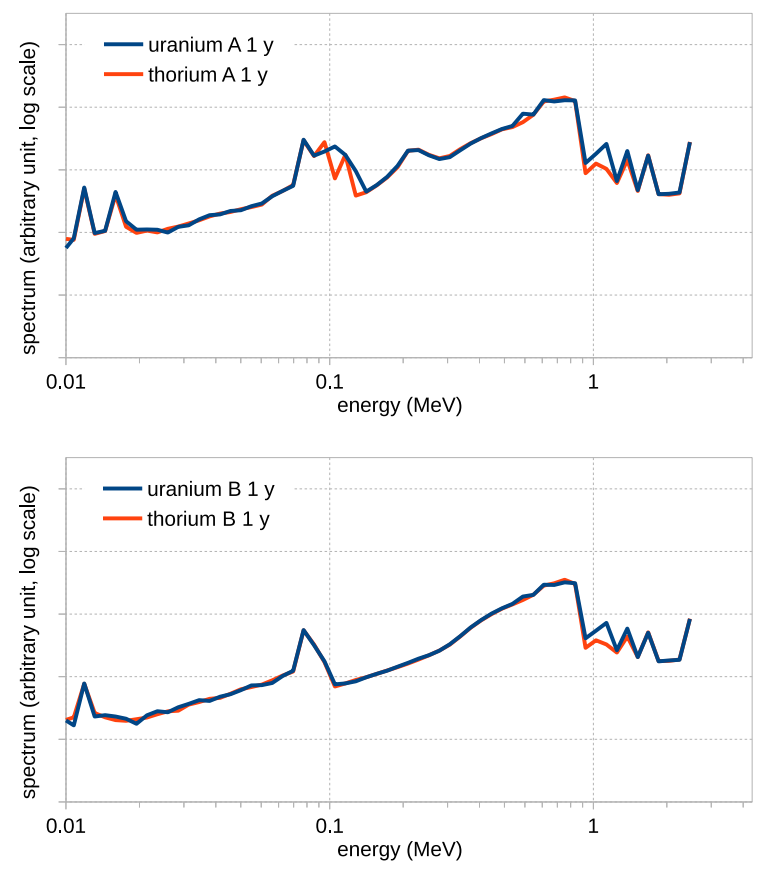

Figure 10: Gamma spectrum in positions A and B after 1 year of decay
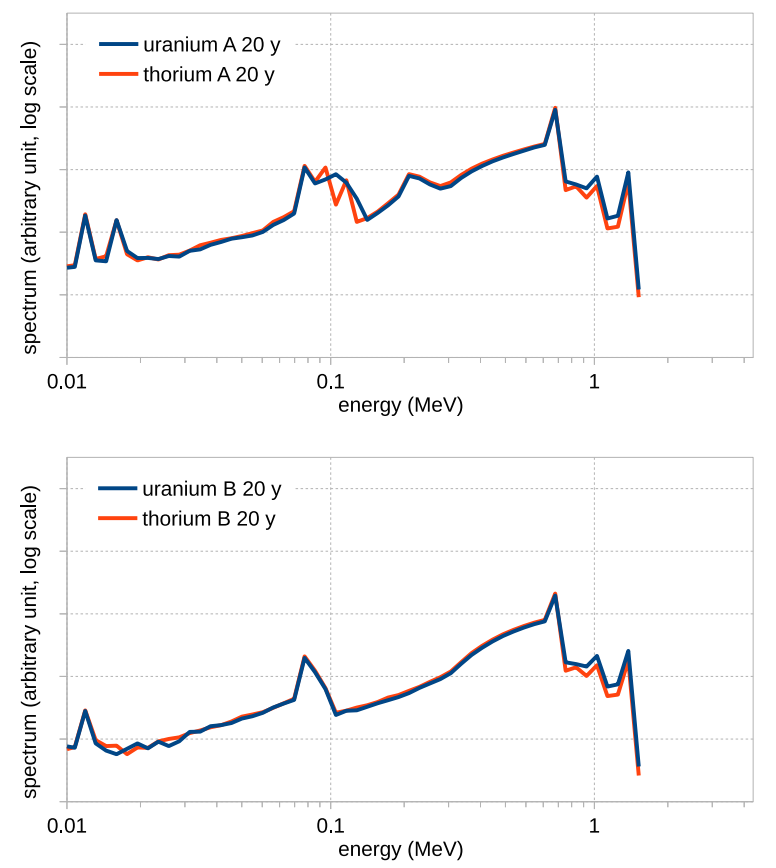

Figure 11: Gamma spectrum in positions A and B after 20 years of decay

depletion can be attributed to rapid decay of ${ }^{233} \mathrm{~Pa}$ present in the spent thorium fuel. Later, the dose rate ratio to the spent uranium fuel is increasing towards the end of the analysed decay time and it is reaching values up to $115 \%$. The included $1 \mathrm{~cm}$ lead shielding does not change the ratio significantly. It was found that this lead layer decreases the dose rate in any case by approximately $96 \%$.

The effect of ${ }^{208} \mathrm{Tl}$ was simulated by its addition to the iso-
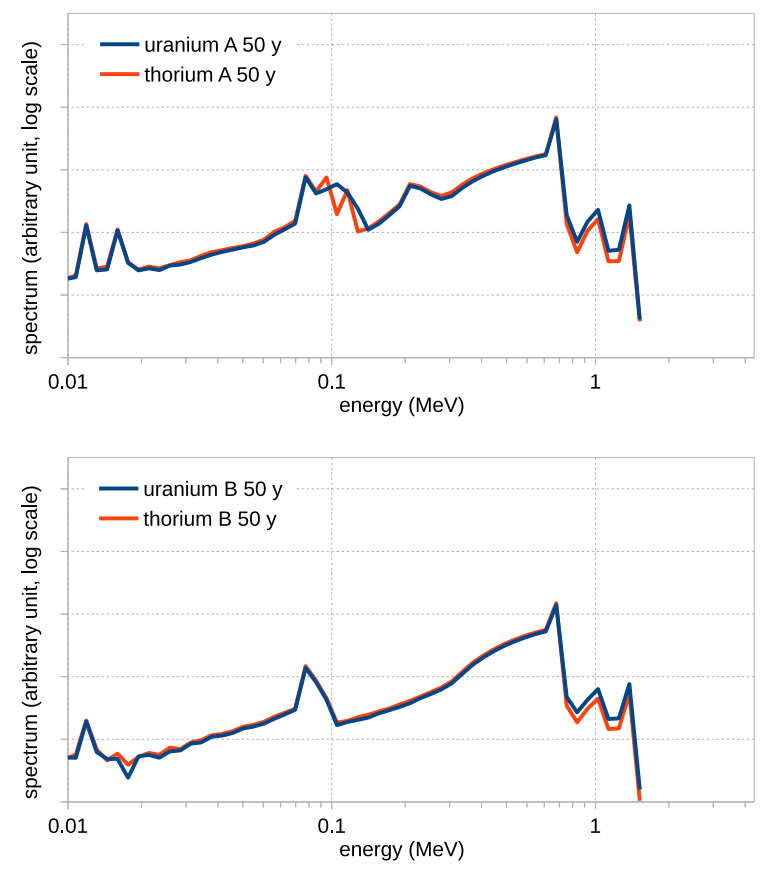

Figure 12: Gamma spectrum in positions A and B after 50 years of decay

Table 5: Ration of spent thorium fuel dose rate to spent uranium fuel and effect of ${ }^{208} \mathrm{Tl}$

\begin{tabular}{ccccc}
\hline time & pos A & pos B & Tl in pos A & Tl in pos B \\
\hline $0 \mathrm{y}$ & $114.3 \%$ & $112.9 \%$ & $100.0 \%$ & $100.0 \%$ \\
$1 \mathrm{y}$ & $100.0 \%$ & $101.0 \%$ & $100.1 \%$ & $100.3 \%$ \\
$20 \mathrm{y}$ & $112.7 \%$ & $111.8 \%$ & $102.2 \%$ & $104.1 \%$ \\
$50 \mathrm{y}$ & $114.6 \%$ & $114.5 \%$ & $103.4 \%$ & $106.2 \%$ \\
\hline
\end{tabular}

topic mixture of the spent thorium fuel with atomic fraction corresponding to its previously calculated ratio to ${ }^{232} \mathrm{U}$ number density (see Fig. 1), which is among actinides present in the spent thorium fuel. There is a clearly observable increase of the calculated dose rate in time reflecting the increasing ${ }^{208} \mathrm{Tl}$ number density and its relative importance. Depending on the time and position the observed difference is in the units of percent. Due to higher penetrability of the $2.6 \mathrm{MeV}$ gamma radiation of ${ }^{208} \mathrm{Tl}$, the dose rate increase is considerably higher in the shielded position $\mathrm{B}$.

\section{Conclusions}

Dosimetry characteristics of the spent thorium and uranium fuels were compared. It was found that default settings of nuclear fuel depletion codes may not be sufficient for correct assessment of dosimetry characteristics of the spent nuclear fuel. This was found for the MCNPX code applied in this analysis. The fuel depletion calculation times are improved by omission of some nuclides, but despite these nuclides may not be important for the neutronic calculation, they may influence the dosimetry characteristics. Strong feature of the MCNPX code 
is the isotopic source definition, which greatly facilitates the user input requirements.

Period of 50 years after the end of fuel depletion is important for spent fuel handling. The spent fuel is loaded into storage pools or storage casks and possibly transported for reprocessing. Even though activity of the spent fuel is decreasing due to decay, it is necessary to know the gamma dose rate from the spent fuel, because it characterize the radiological hazard associated with spent fuel handling.

Uranium and thorium spent fuel compositions were determined by MCNPX calculation of fuel depletion. A decay period of 50 years was simulated afterwards. Characteristics of the spent thorium fuel were determined relative to the spent uranium fuel. The results were presented separately for fission products and actinides. Fission products are dominant for the spent fuel characteristics in the analysed period, but the major differences were observed for actinides, which are more important in the long-term perspective.

It was found that the dose rate from the spent thorium fuel relative to the spent uranium fuel is increasing in the analysed period and it is greater by almost $15 \%$ after 50 years of decay. This difference is a result of distinct actinide compositions, because the observed differences in fission products remain stable over the analysed period.

The level of discrepancy in the dosimetry calculations caused by insufficient spent fuel characteristics determined by the fuel depletion codes was tested for ${ }^{208} \mathrm{Tl}$. It is missing in the spent thorium fuel composition. It was introduced in the spent thorium fuel mixture with number density relative to ${ }^{232} \mathrm{U}$ (determined by separate calculation). this single nuclide accounted for a dose rate increase in the range of units of percent. Due to higher penetrability of the $2.6 \mathrm{MeV}^{208} \mathrm{Tl}$ radiation, the relative increase is approximately double in a calculation position shielded by $1 \mathrm{~cm}$ lead shielding.

In summary, higher radiological hazard associated with spent thorium fuel was clearly demonstrated by comparison with spent uranium fuel. Further analysis should be conducted to find other possible spent fuel components (even of uranium fuel) important from the dosimetry point of view but neglected by fuel depletion codes.

\section{References}

Frybort, J. and Vocka, R.: Usage of Thorium Based Nuclear Fuel in VVER reactors, Proceedings of ICAPP'10, San Diego, CA, USA

Kang, J. and von Hippel, F.N.: U-232 and the Proliferation Resistance of U-233 in Spent Fuel, Science \& Global Security, Vol 9, pp 1-32

Pelowitz, D.B.: MCNPX User's Manual, LA-CP-11-00438, USA

Chadwick, M.B. and Oblozinsky, P. and Herman, M. at al.: ENDF/B-VII.0: Next Generation Evaluated Nuclear Data Library for Nuclear Science and Technology, Nuclear Data Sheets, vol. 107, pp. 2931-3060, 2006.

Breza, J. and Darilek, P. and Necas, V.: Study of thorium advanced fuel cycle utilization in light water reactor VVER-440, Annals of Nuclear Energy 37 (2010) pp. 685690

Cacuci, D.G.: Handbook of Nuclear Engineering, ISBN 978-0-387-98130-7, Springer, 2010 